\title{
L'ESTRUCTURACIÓ DE L'ORACIÓ COMPOSTA EN EL Tirant lo Blanc
}

1. La llengua de Joanot Martorell en el Tirant lo Blanc exigeix una especial atenció. Dins l'àmbit de les literatures romàniques la novel.la representa una fita ben important en l'expansió del Reinaxament italià per Europa' que tant havia d'influir en una nova consideració del fet artístic. Es impossible no pensar en Boccaccio com el iniciador de la prosa de grans pretensions literaries.

No creiem arriscat afirmar que Joanot Martorell fou bon coneixedor de la literatura italiana. ${ }^{2}$ Un any llarg, el 1454 , el passà a Nàpols. Les reminiscències italianes en conseqüència, i no sols de caire literari, no manquen. Fins al punt de que bona part de l'acció de la novel.la es desenvoluparà a Sicília, dins la cort aragonesa de Palerm. La història del filòsof de Calàbria (capt. 110), tot i conservar records bíblics abundant en l'episodi de l'empresonament i tenir com origen remot un conte de les Mil i una nits (recordem el motiu del cavall d'orelles caigudes; del riquíssim balaix amb cuc), és tanmateix una reelaboració de la narració tercera del Novellino, recull literari italià del segle XIII.

2. La crítica filológica ha establert el doble estil en que es presenta la novel.la. No podem dubtar d'aquesta afirmació. ${ }^{3}$ La diferéncia d'estil -d'identificació prou fàcil per el que pertoca al lèxic-, necessita d'unes observacions relatives a l'estructuració del període, de l'oració composta.

L'autor agraeix al gentil collega Jordi Canals Piñas la traducció al català i els seus consells pel que fa al tema tractat.

1 Tot i així, no hem d'oblidar la intensa difussió de la cultura italiana en època d'Alfons V el Magnànim.

2 Fem sempre referència als treballs de Martí de Riquer, en especial de la introducció a Tirant lo Blanc, /Editorial Ariel/, Barcelona 1969, així com a Martí de Riquer - Antoni Comas, Història de la literatura catalana, vol. III, Barcelona 1964.

3 De Riquer, Història, p. 390: - Dos estils s'entrecreuen en la prosa del Tirant. Per una banda el to solemne, oratori, subjecte als cànons de la prosa renaixentista i a la "valenciana prosa". Ací Martorell, $\mathrm{i}$ potser en major proporció Galba, ens apareixen com a seguidors d'una moda literária, i els parlaments, lamentacions, preguntes, respostes, reprensions, conhorts que trobem a tot el llarg de la novel.la són molt sovint forçats i eixuts (...) Però aquest estil culte i filigranat, fins i tot pedant, si es vol, no és tan arbitrari ni tan fals com pot semblar a primera vista (...) allà on el Tirant lo Blanch esdevé inoblidable i manté uns valors que rep agradosament el lector modern és quan Joanot Martorell, bandejada tota retórica, fa parlar els seus personatges en un diàleg breu, tallant i familiar. La prosa adquireix ales hores un delicios to col.loquial, ple de matisos i de gràcia on les expressions casolanes, els refranys, els jocs de paraules i les vives exclamacions fan del Tirant la millor novel.la catalana. 
No cal comprobar com l'estructuració del diàleg és diferent de l'emprada en la narració. Amb raó la natura sap impedir la formació de cadenes de sons excessivament llargues. D'altra banda, hi intervé un cert respecte cap l'oient, ja que el parlant no pot correr el risc de presentar-li una massa amorfa. Si això és vàlid per a un diáleg real, és vàlid tanmateix per a un diàleg escrit.

Ens interessa ara aquí la narració d'en Martorell per a la que no cal exagerar la indubtable influència italiana de derivació "boccaccesca". Ens és possible establir que l'estructuració del període en el Tirant pot assolir complexitat, però ben poques vegades arriba a la complicació. Tractarem d'ilustrar el que cal entendre com estil boccaccesc amb un fragment del Decameron III, 3 en el seu original, seguit d'una traducció catalana tan sols de pocs decennis anterior al Tirant i, per aquesta raó, tan important per a la finalitat del nostre treball: ${ }^{4}$

Costei adunque d'alto legnaggio veggendosi nata e maritata ad uno artefice lanaiuolo, per ciò che richissimo era, non potendo lo sdegno dell'animo porre in terra, per lo quale estimava niuno uomo di bassa condizione, quantunque ricchissimo fosse, esser di gentil donna degno, e veggendo lui ancora con tutte le sue ricchezze da niuna altra cosa essere piú avanti che da saper divisare un mescolato o fare ordire una tela o con una filatrice disputare del filato, propose di non volere de'suoi abbracciamenti in alcuna manie$\mathrm{ra}$, se non in quanto negare non gli potesse, ma di volere a soddisfazione di se medesima trovare alcuno, il quale piú di ciò che il lanaiuolo le paresse che fosse degno.

Aquesta, donchs, era nada de gran linatge, per raó del qual un ome apellat Artiffice Lanavioli /en nota: En lloc de "artesà llaner"/ la pres per muller, e, no contrestant que fos molt rich, no podia lo desdeny de la ànima sua aportar la terra per co com estimava que nengú de baxa condició, posat que fos lo pus rich que esser posqués, no era dichne de aver jentil dona per muller; a veent lo tal que encara, ab tota sa riquesa, de nenguna altra cosa no era pus avançat ne presat que de saber divisar una tela de seda com se devia hordir, e per semblant de lli, e ab una filetera disputar si era ben filat o mal filat, proposà en sí de lunyar-se de sos abraçaments e en nenguna manera no acostar-se a ell, ans tant com podia lo y denegava. Mas per voler a sa voluntat satisfer servà trobar manera per aver algú lo qual li paragués que fos pus dichne que Lanaviolo.

Respecte a l'original italià, la traducció catalana s'ens presenta si més no alleugerida; mercès sobretot a la puntuació, el que equival - pel que fa al nivell de la parla - a pauses en el discurs.

3. Nombrosos fragments ens demostren que el període del Tirant no és d'estructura simple. N'hi hauria prou amb citar com a prova l'inici de la novel.la:

E per tant com la divina Providència ha ordenat e li plau que los set planets donen influència en lo món e tenen domini sobre la humana natura, donant-los diverses inclinacions de pecar e viciosament viure, emperò no els ha tolt l'universal Creador lo franc arbitre, que si aquell és ben regit les poden, virtuosament vivint, mitigar e vençre, si usar volen de discreció, 1;

4 Joan Boccaccio, Decameron. Traducció catalana publicada segons l'unic manuscrit conegut (any 1492), /Editorial AHR/, Barcelona 1964. 
Com la senyora conegué que prou l'havia espletat, donà-li comiat dient-li que altre dia, com se seria descansat, poria tornar dins en la cambra e poria pendre d'ella tot lo que plasent li fos, 262.

$\mathrm{Si}$ aquestes oracions compostes no tenen ni molt menys l'amplitud de les oracions del Decameron, sí és cert tanmateix que hi trobem una equivalent construcció dels períodes breus que veiem reflectida en el segon dels fragments. Hi ha en el període oracions subordinades de tot tipus $i$, a més a més, entre elles implícites d'infinitiu, de gerundi i de participi. Es tracta doncs d'un estil proper al de Boccaccio tot i no presentar excessiu grau de complicació; de longitud semblant a la del fragment del Decameron, però menys complex. Caldrà cercar el motiu en el fet de que Martorell descriu els esdeveniments ben sovint sota forma de diàleg, al temps que en l'obra italiana preval la narració. Com a consequiència, el nombre de subordinades implícites en relació amb el recull novel.lesc italià és menor, tot i que les caracteristiques lingüístiques i estilístiques clàssiques, com són ara les estructures d'inspiració llatina o elements estilístics "boccaccescs", es presenten al llarg de tot el llibre. ${ }^{5}$

Hi trobem l'infinitiu àdhuc com part integrant de la clàssica estructura d'acusatiu o nominatiu amb infinitiu, tal com podem veure en els exemples següents: per jo ésser parent de Tirant, 119; Sobre les tues armes he vist portar hàbit de donzella : mostres, segons lo senyal, ésser enamorat d'ella, 150; Com per la tua trompeta he rebuda una lletra tua en què dius haver-me vist portar sobre les armes hàbit de donzella (...) Venint a l'efecte del que vull dir, dius jo haver desconfit dues voltes lo vostre camp ab maldat e tració, 152.

S'ha de fer notar que els dos darrers fragments, corresponents als capítols $150 \mathrm{i}$ 152 , són frases que procedeixen de dues cartes o lletres de batalla — del rei d'Egipte i de Tirant respectivament - , escrites ambdues en un to ple de grandilocuència (poc importa que el rei insulti en Tirant), fidel a un codi caballeresc $i$ amb el resultat d'una més gran elaboració estilística. No ens ha de sorprendre, per tant, un vocabu-

5 És útil transcriure el judici de Parodi, "La cultura e lo stile del Boccaccio" in Poeti antichi e moderni, Firenze 1923, p.161: - Lo spirito del Boccaccio fu venato di alessandrinismo fin dalla nascita, e l'amore del peregrino, del lussuoso, del complicato, del sovrabbondante si mescolava in lui in indissolubile unione col più puro e schietto realismo, minacciando sempre di trionfare. Sulla sua nuova anima borghese-mercantile di fiorentino un'altra misteriosamente se ne accendeva, di un OvidioApuleio. Apud Migliorini, Storia, della lingua italiana, Firenze 1960, p. 208.

Ans al contrari, l'estil de Cervantes ha estat jutjat com de mancada complicacio; cfr. Hatzfeld, 'Don Quijote' als Wortkunstwerk, Leipzig-Berlin 1927, p. 238: - Um uns aber unter Boccacciostil von vornherein eine Bestimmte Vorstellung machen zu können, wollen wir den Begriff einmal vorläufig mit dem Worte grob umschreiben, das sich dem Italiener mit dem Begriffe Boccacciostil zwangsläufig verbindet, nämlich mit periodare. Die Prosakunst des Periodare wird meistens nur syntaktisch gewürdigt, als die majestätische Folge von hypotaktischen Satzgebilden, in denen sich Bedingungs-, Folgerungs- und Einräumungssätze mit ihrem Hyperbaton und ihren gleichmässig abgezirkelten Satzlängen, Digressionen und Parenthesen ununterbrochen ablösen. Das versteht man im allgemeinen unter der klassizistischen Periode, dem dire classico. In all diesen Dingen ist Cervantes mit seiner Vorliebe für die Parataxe und die syntaktische Klarheit in "Don Quijote" entschieden von Boccaccio abgerückt. - Schwere hypotaktische Satzgebilde nur vereinzelt (Curiciso impertinente, Española, Inglesa, Fuerza de la sangre). 
lari més escollit i si cal més distingit, així com el fet de que l'autor empri formes verbals no personals (veurem més endavant exemples de gerundi). Un to elevat en correspondència amb una adequada selecció lingüística trobarem tanmateix en els parlaments d'alguns personatges. ${ }^{6}$ Així el de Tirant, que d'aquesta manera obre el "raonament sobre lo matrimoni de la infanta Carmesina":

La celsitud de vostra excellència, senyora de totes virtuts complida, me fa estar admirat, per ésser vós la mès discreta donzella que jo jamés haja conegut que vol l'altesa vostra fer procès de pensa a Felip, lo qual (salvant la honor de l'excellència vostra) no proceeix de justícia ni menys de caritat, per ço com Felip és hui u del bells cavallers del món, 110

o en "La resposta que Tirant féu al duc de Macedònia":

Si creeu que per ésser antics vostres mals actes, sien fora de la memòria de les gents (...) mal creeu, e ja per tolre-us d'haver oir alguna part de vostres gloriosos actes, e de representar a mi la llegea d'aquells, prou clarament se mostra jo haver-vos comportat les coses que cascun jorn vós deixau dir de mi (...) quant per alguns esguards coneixereu vós haver la llengua llaugera (...) e per ço nomenen a vós perdedor de batalles, com no sia estada sol una batalla vós haver vençuda, 154 .

D'altra banda hi ha oracions compostes on en lloc d'una possible construcció d'infinitiu s'ha escollit una subordinada explícita. Per exemple, darrera de verbs sentiendi et dicendi o de manament: E Tirant la suplicà que li donas la mà, 125; Jo et prec que els vulles posar en altre lloc, 220 i Senyora, nosaltres parlam d'aquestes gents que dien que han portat los genovesos en ajuda dels moros, 125; Manà l'Emperador que tocassen totes les campanes de la ciutat, e tothom anàs a l'esglesia de Santa Sofia, 134.

En el text hi ha tanmateix gerundis i participis. Per causa de la imatge fonica, els de present no es diferèncien dels gerundis. Si en la major part dels casos els gerundis (o participis de present) mostren un valor relatiu i fan concordància amb el subjecte, com en la frase $E$ trobant-se lo virtuós Comte en edad avançada de cinquanta-cinc anys, mogut por divinal inspiració proposà de retraure's de les armes, 2, més significatius són els fragments on podem constatar un ús absolut: Concordes de nostra batalla, venint al jutge dieu competent, ¿qui serà dit jutge competent? (...) Havent tu de mi lo que desiges, qui et pot assegurar de mos parents et amics tu tornasses dins lo teu camp? (...) A tots és notori, estant vosaltres ab tot lo vostre poder tenint assejat l'il.lustre duc de Macedònia, jo ani a cercar a vosaltres $e$ us desconfí, 152. Totes tres oracions han estat tretes de la resposta de Tirant a la lletra de batalla del rei d'Egipte; és a dir, un cop més ens trobem en presència d'un estil mínimament enlairat. Amb excepció de paràgrafs d'evident intenció literària, hi ha un ús força limitat del gerundi: Molt fon plasent a Tirant la venguda dels ambaixadors, més que no fon al Rei pensant e havent record de les paraules del Mestre de

6 Quelcom de semblant fa Cervantes; $\mathrm{cfr}$. les paraules enlairades que Quixot dirigeix a la llunyana Dulcinea. 
Rodes, (...) Així passejaren per la ciutat prenent molt plaer la Infanta com veia banyar la roba d'aquell miserable de Felip, 109; E estant en aquestes raons /sc. lo filòsof i lo cavaller/ l'alguazir entrà en la presó e tragué lo cavaller, 110; car treballes d'apartar de mi la molta amor que et porte, volent tu usar de poder absolut devers $m i, 281$. El ús absolut, és a dir independent de la forma implícita, s'assegura mitjançant la falta de concordància estructural d'ambdues oraciones; amb prou feines poden respectivament ésser considerades subordinada i subordinant $o$, si més no, cal dir que foren de dèbil règim.

Molt infreqüent és l'ús absolut del participi, sempre tingut com caracteristic de l'estil literari: Arribats que foren ${ }^{7}$ ab Tirant, no fon poc lo plaer que pres en llur venguda, 148; Complit l'ofici e les banderes posades, e tota la gent fon fora de la esglesia, 281.

4. L'estructuració de l'oració composta en el Tirant s'ens presenta de manera força simple, i amb aquesta afirmació volem donar a entendre la relativa raresa de construccions implícites. És freqüent en canvi la subordinació amb explícites, tot i que de tant en tant ens sorprendrà el recurs a la parataxis. Llegim en el capítol 125:

Elles se levaren. Tirant pres per lo braç a l'Emperadriu, e Diafebus a la Princesa. Anant per lo palau veren molts bells edeficis. Com foren a la torre del tresor la Princesa obrí les portes per ço com ella tenia totes les claus. La torre era tota dins obrada de molt blanc marbre, e historiada de subtil pintura de diverses colors tota la història de Paris e Viana; e tota la coberta d'or e d'atzur...

De tota manera, cal afegir l'observació de que la coordinació pura és molt infreqüent $i$, a més a més, no sembla pas mai constituir un mitjà estilístic.

5. Arribats a aquest punt, ens convé deixar momentàniament de banda el llenguatge de la novel.la caballeresca d'en Martorell amb la finalitat d'apropar-nos al llenguatge de les grandes cròniques catalanes. ${ }^{8}$ Certament el llenguatge d'una crònica no és el mateix d'una novel.la. Tot i així, la crònica és sempre una obra literària que descriu esdeveniments passats. Les cròniques catalanes, molt anteriors al Tirant, reflecteixen una estructuració del periode molt més simple que no pas aquest: molta coordinació; molt polisíndeton, característica que ens recorda l'estil bíblic; poca subordinació (o al menys, limitat l'ús de les subordinades a l'especificació o a la descripció). Els esdeveniments es descriuen amb senzillesa per mitjà de l'oració coordinada. A títol d'exemple, n'hi haurà prou amb la consideració del següent fragment extret del Libre dels feyts, crònica del regnat de Jaume cap. 414:

Entorn a la col.locació estilística del participi, cfr. Škerlj, Osservazioni sul carattere, dotto o popolare che sia, dei costrutti giunto che fu, bello com'è e simili, Atti dell' VIII Congresso internazionale di Studi Romanzi, II, Firenze 1969, pp. 423-435.

- Hem consultat Crònica de Jaume I, Crònica de Bernat Desclot, Crònica de Ramon Muntaner, Crònica de Pere el Cerimoniós. Totes les cites procedeixen de Les quatre grans cròniques, /Selecta/, Barcelona 1971. 
E enviam sempre un missatge a Petrer que En Jofré havia perdut, e tantost vengren dos dels vells a nós, e un jueu que hi estava en temps d'En Jofré, e els sarraïns no l'havien negun mal feit, e parlam ab ells que retessen lo castell a nós, e nós que el retríem a En Jofré.

Tanmateix és útil apropar-nos a la crònica de Ramon Muntaner (un segle anterior al Tirant), d'on escollim un paràgraf relatiu a les vespres sicilianes:

E entre les altres malvestats esdevenc-se un dia, que eren festes, e a Palerm ha una esglesia que és vers lo pont de l'Almirall, e en les festes de Pasqua ix tota la ciutat de Palerm a perdonança, e majorment les dones de Palerm hi van totes. E aquell dia anaren-hi algunes gentils dones entre les altres, qui eren molt belles dones, e els sarjants franceses eixiren defora e trobaren aquelles dones que anaven acompanyades de bons jóvens, llurs parents. E per ço que a les dones poguessen metre la man on se volguessen en llur persona, cercaren los jovens homes si portaven armes, e con veeren que no en portaven dixeren que a les dones les havien comanades, e escorcollaren les dones, e per les maneres ells los metien la mà, e les pessigaven, e mitien-los les mans a les mamelles així mateix. Així que los jovens qui anaven ab les dones, qui veeren aço e veïen que batien ab vergues de bou aquells e aquelles qui d'aço s'esquivaven, e cridaren a Déu: - Pare senyor, tanta de superbia, qui la porà soferir?

par. 43.

La llengua de les grans cròniques catalanes sembla no haver sofert el contacte de la prosa del Trecents italià; l'estil del incipient Renaixament és encara aliè al gènere.

6. Hem pogut constatar que Martorell no fa mai recurs a una hipotaxis excessivament complicada. Amb aixó no volem pas dir que la hipotaxis no sigui el mitjà més natural no sols per a la narració d'esdeveniments, sino també per a la construcció de diàlegs en estil directe, tot i que l'oració composta és relativament breu.

El darrer punt que aquí ens interessa analitzar és el de l'estructura de l'oració composta. Totes les gramátiques tracten de l'oració simple, si bé no n'hi ha cap que es plantegi problemes pertinents a l'ordre dels seus elements constituents. D'altra banda no s'ha d'insistir en la importáncia que té la col.locació dels elements dins d'un sintagma, com és ara la posició de l'adjectiu que tant rellevant és per a les llengues romàniques. Tot i aixi, les gramàtiques que estudien l'oració composta categoritzen i analitzen les subordinades, però descuren el probleme de llur col.locació amb respecte a l'oració principal. ${ }^{9}$

La dificultat en conseqüencia persisteix. Es tractarà en pàgines següents de veure en quina manera Martorell construeix un període. A grans trets podem dir que l'estructuració del període respecta exigències psicològiques $\mathrm{o}$, amb altres paraules, que l'ordre de les diferents subordinades obeeix a la disposició mental del parlant.

9 Ni Gili Gaya en el Curso Superior de Sintaxis Española, ni Badia i Margarit, a Gramática catalana tracten en absolut d'aquest punt; tot i dedicar el darrer força espai a les oracions subordinades (pp. 241-284, vol. II, ed. Madrid 1962). 
La subordinada ocupa el lloc, dins el període, exigit i condicionat per l'enunciandum que equival al contingut que el parlant vol expressar.

Dins de l'estructuració del periode hi ha unes constants, justificades per l'especial disposició psicològica del parlant. Així, entre les completives, ens adonem que una objectiva segueix a la subordinant. Es poden comparar els anteriors fragments citats del capítol 220, amb els següents: Com los moros saberen que lo Rei s'era partit de la ciutat de Londres, seguiren-lo fins que saberen que s'era recollit dins la ciutat de Varoic, 5; E l'Emperador li dix que callàs e que no digués que ell fos allí, 220.

Una subordinada subjecte segueix a la subordinant, com per exemple: Comtessa, a mi par que vós me donau bon consell, 5; Qui dóna consell-dix Plaerdemavidaforçat és que hi pose del seu, 229; Gran gloria és per a mi que les mies mans hagen usat de novell ofici, 281. Les subordinades subjectives que precedeixen a la subordinant són una minoria. En el capitol 229 trobem encare: $E$ no sabeu vós que moltes voltes s'esdevé que qui mal consell creu no pot ésser que alguna volta no li'n vinga dan e deshonor.

Naturalment una subordinada relativa es col.loca darrera la principal; és normal que segueixi la subordinant amb un antecedent al que fa referència la relativa, sigui aquesta especificativa o explicativa: Los moros, fent aquella via, combateren un castell e prengueren-lo, qui es nomenava Alimburg, qui era a dues llegües on estava lo Rei, 5; Com Tirant hagué oïda l'ambaixada pensà en la promesa fe que fet havien, 349.

Molt més complicada s'ens presenta l'ordre de les subordinades adverbials. Com a norma general, precedeixen a la principal o a la subordinant les subordinades que en certa manera preparen, condicionen o impedeixen la realització de l'acció principal, o bé que la precedeixen en la cadena temporal. Precedeixen aleshores a la subordinant lògicament les temporals: Com se'n fon anat, Plaerdemavida estava tan tribulada que més no podia, 281; Com la missa fon dita, totes les banderes foren posades, 281; així com les condicionals i les concessives: E si jo tingués ceptre real, o de l'Imperi grec jo fos senyora e de les mies entràmenes Carmesina fos eixida, bé sé jo a qui la donara per muller, 229; E per quant sou ma senyora natural, qui seria venir contra la fidelitat, quinsevulla sagrament que jo haja fet, no val res, 215 .

Quan ben contrariament la condició continguda dins la subordinada no és una condició veritable, la realització de la qual és presentada com indispensable per a la realització de l'acció espressada amb verb de la subordinant, si no es una condició genèrica com és ara una reflexió personal afegida al que s'ha dit amb anterioritat, observarem que condicionals i concessives segueixen la respectiva subordinant: Emperò no els ha tolt l'universal Creador lo franc arbitre, que si aquell és ben regit les poden /inclinacions de pecar/, virtuosament vivint, mitigar e vençre, si usar volen de discreció, 1; Jerusalem, on tot cristià deu anar, si li es possible, $2 ;$ E feta la deliberació, en la nit manifestà a la Comtessa, muller sua, la sua breu partida, la qual 
ho pres ab molta impaciència, per bé que fos molt virtuosa e discreta, $2 ; E$ certament qualsevulla dona o donzella qui en tal so la mireu vos parrà molt lleja per gentil que sia, 231.

En totes aquestes citacions la subordinada sembla poc lligada a la subordinant; d'altra banda, menys que una condició és perceptible un matís d'eventualitat, com és ara si, eventualment, usar volen...

Segueixen a la principal totes les consecutives, totes les finals, totes les modals. Una ordenació més que natural ja que són expressió d'una consequència, troben origen en un altra situació, $i$ una modal ha de fer referència a un fet expressat amb anterioritat. Així trobem: E tant mostrà lo dit Rei amar-la, que no la volgué jamés casar en sa vida, 229; Tirant estava alienat, que no pogué parlar per la vista de tan singular dama, 229; Plaerdemavida (...) posà roba dessús perquè neguna de les altres no ho vessen. (...) li parà lo siti que venia en dret que Tirant la podia molt ben veure, 231; Almenys feu-me gràcia que jo vaja ab vós perquè us puga servir, 3 ; E havia-hi una gran caixa ab un forat que hi havien fet perquè pogués alendar, 231.

Algunes vegades a l'expresió de conseqüència s'hi afegeix el matís de finalitat, d'on deriva l'us del subjuntiu. Certes subordinades són decididament finals, tot $\mathrm{i}$ que no hi ha un límit ben exacte; les dues idees, de conseqüència i de finalitat, tenen un mateix denominador: una realització virtual i posterior a l'acció o situació expressada amb la subordinant.

Aixó també és aplicable a les modals, que presenten la manera de realització de la principal, de vegades un terme de comparació amb aquesta.Ès lògic, per tant, que una subordinada modal segueixi a una subordinant: No vulles $t u /$ rei/fer així com feu aquell rei de Proença que tenía una molt bellíssima filla, 229; la feminil condició promptament no pogué resistir que no demostràs ésser molt agreujada, 2. Igual ordenació trobem dins un grup especial de modals: les introduïdes amb la conjunció "que" de valor genèric: Ell ana-hi de continent e trobà'l que es vestia, 229. El valor real de la subordinada és quasi bé el de una coordinada. Un cas semblant presenten les aparentment causals, on l'ordenació darrera de la pretesa subordinant assegura un valor conclusiu: Que els /gats/vulles posar en altra lloc, que no me lleixen dormir, 220. És evident que la subordinada, formalment subordinada, no expresa la causa de l'acció continguda dins el verb de la subordinant. Per norma general, les causals (infreqüents en realitat a la novel.la), precedeixen la principal: Per ço com tant de temps vos he tengut en los meus braços, e mamat haveu de la mia llet, tinc desig de cercarvos honors e delits, 215.

7. Le llengua del Tirant pel que fa a l'estructura de l'oració composta es col.loca a mig camí entre el Decameron i El Quixot, i sens dubte més proper al darrer. Si les cròniques catalanes són alienes a la influència literària italiana, la llengua del $T i$ rant demostra tenir com a model la prosa italiana. Cal però subrattlar que aquesta influència es manifesta amb força en paràgrafs d'evident intenció estètica, de nom- 
bre limitat, abundosos tanmateix de reminiscències sintàctiques de derivació llatina (subordinació implícita, ús de participis, gerundis, infinitius). Pel que fa a la resta, la construcció de periode és ben diferent de la que és possible trobar en el Decameron: molt diàleg, molt estil directe i narració inmediata. L'estructuració del període sembla condicionada per les exigències psicologiques: les subordinades que preparen, condicionen, expressen la causa o cronologicament precedeixen els esdeveniments expressats en les oracions principals, situant-se davant d'aquestes; excepció feta dels casos en que afegeixen tan sols una condició de realització eventual que formalment enllacen amb la subordinant.

Ben al contrari, les subordinades que determinen l'oració principal o un element d'aquesta - relatives específiques i explicatives - es col.loquen darrera d'ella. Tanmateix pel que fa a les subordinades que expressen una finalitat o una conseqüència - a vegades àdhuc aquestes amb un matís de finalitat -, o bé que delimiten la manera en que ha estat realitzada l'acció de l'oració principal. Segueixen també al darrera les subordinades comparatives, doncs presenten l'element comparatiu a la subordinant. Per últim, els períodes que admeten una doble col.locació de la subordinada - situació anàloga, tot i que no idèntica a la del sintagma sustantiu-adjectiu - proporcionen a la subordinada situada davant la subordinant un matís d'enllaç més íntim; i a la que segueix darrera, una independència sintàctica i semàntica.

Povzetek

ZGRADBA POVEDI V KATALONSKEM VITEŠKEM ROMANU Tirant lo Blanc

Najpomembnejక̌e delo zgodnje katalonske književnosti, viteški roman Tirant lo Blanc kaže v svojem jeziku neko dvojnost, vidno tudi v zgradbi povedi. Avtor, Joanot Martorell z ene strani posnema izdelani in zapleteni stil italijanskega trečentista Boccaccia (dolge in zapletene periode, obilje odvisnikov $z$ neosebnimi glagolskimi oblikami), z druge pa je gradnja povedi dokaj enostavna. V nasprotju z Dekameronom ima namreč katalonski roman veliko dogajanja povedanega v premem govoru; ta pa je enostavnejši.

V zgradbi povedi je mogoče ugotoviti nekaj stalnic: časovni, vzročni, pogojni in dopustni odvisniki stojijo pred glavnim stavkom, saj ga nekako uvajajo; objektni, primerjalni, zlasti pa prilastkovi in posledični pa mu sledijo. Nekateri odvisniki dopušcajo obe stavi in tako postane stava odvisnika stilistično sredstvo: tista pred glavnim stavkom kaže tesnejక̌o povezanost med obema elementoma povedi. 